\title{
Dynamic change of the Yellow River Delta Using Historical Data and Remote Sensing Imagery
}

\author{
X.Y. Yu ${ }^{1,2}$ W.J. Zhao ${ }^{3} \quad$ T.T. Yan ${ }^{4}$ \\ ${ }^{1}$ College of Resources and Environment, Shandong Agricultural University, Tai 'an, Shandong \\ province, China \\ ${ }^{2}$ Institute of Geographic Sciences and Natural Resources Research, Chinese Academy of \\ Sciences, Beijing, China \\ ${ }^{3}$ School of Tourism, Taishan University, Tai'an, Shandong province, China \\ ${ }^{4}$ School of Business, Taishan University, Tai'an, Shandong province, China
}

\begin{abstract}
Keyword: Dynamic change; Yellow River; Yellow River Delta; Land recession
Abstract: Historical data since 1855 and Landsat remote sensing images for the year 2006, 2009 and 2013 were selected as the main data sources and RS/GIS spatial analysis tools were combined to investigate the mouth channel change of Yellow River and monitor the dynamic change of Yellow River Delta. The results demonstrated that since the Yellow River changed its trajectory into Bohai Sea in 1855, its mouth channel migrated ten times and displayed various patterns; during 2006-2013, the area of Yellow River Delta was reduced by $18.54 \%\left(86.25 \mathrm{~km}^{2}\right)$. Considering land recession will bring about serious effects, decision makers shall implement effective policies in advance to combat various ramifications caused by land decreasing.
\end{abstract}

\section{Introduction}

The Yellow River of China, or Huang He, is the third-longest river in Asia at an estimated length of $5,464 \mathrm{~km}$. Originating from the Bayan Har Mountains in Qinghai province of western China, it flows eastwards through nine provinces, emptying into the Bohai Sea of China. As the first highest sediment loaded river in China (Milliman \& Meade, 1983), the Yellow River carries billion tons of mud and sand per year to its lower reaches, elevating the river bed, and extend the area of Yellow River Delta (YRD) significantly since 1855, makes it the sole "growing land in China" (http://earthobservatory.nasa.gov/Features/WorldOfChange/yellow_river.php). Recently, the YRD has undergone rapid economic development and is considered one of the key regions in China's future economy (Wang et al., 2012). Accurate mapping and detecting change of YRD is of great importance in biodiversity protecting and socio-economy development.

From the year of 1950, dams and reservoirs along the Yellow River together with the soil and water conservation policies implemented in the upper and middle reaches gradually retain most of its sediments. As previous studies reported, the annual average sediment discharge of Yellow River during 1950-1968 was $12.26 \times 10^{9}$ metric tons, then $8.34 \times 10^{9} \mathrm{t}(1968-1985), 3.30 \times 10^{9} \mathrm{t}$ from 1986 to 2002 , and during 2001-2005, the sediment load was merely $1.51 \times 10^{9} \mathrm{t}$ (Peng et al., 2010), one eighth of that during 1950-1968. The riverine sediment supply has been reduced, and global sea level is rising (Wonsuck, 2012), commonly leading to prominent physical, ecological and geomorphological effects on YRD (Wang et al., 2007). Whether the Yellow River is still building land becomes a topic of public concern.

Since 1970s, the increasing availability of remote sensing images with appropriate spatial and temporal resolution facilitates the monitoring and understanding of land cover change from regional to global scales, various institutes studied the yellow river using RS imagery as the main data source (Ottinger et al., 2013; Ye et al., 2004).

The focus of this study is to analyze changes in the natural environment of YRD in context of the mouth channel change and socio-economic developments. To investigate the mouth channel change of the Yellow River since 1855, we collected historical data on mouth channel changes; to evaluate dynamic changes in YRD, we combined remote sensing imagery during 2006-2013, and we applied 
remote sensing analysis together with GIS spatial analysis tools to explore changes in the deltaic environment. The utilization of spatial analysis can enhance the understanding of recent land cover processes in YRD.

\section{Study area}

Since 1855, the Yellow River changed the trajectory of its lower reaches into the Bohai Sea. Until now the entire drainage basin covers an area of more than $750,000 \mathrm{~km}^{2}$ (Wang et al., 2007). In this paper, we selected Dongying city as the case study area to detect and monitor the dynamic change of YRD. Dongying city is a prefecture-level city lying on the northern coast (Bohai Sea) of Shandong province China (Figure 1). According to the 2014 census results, there were 2,035,338 people resided within its administrative area of $7,923.26 \mathrm{~km}^{2}$. Dongying city is home of the Shengli Oilfield, which is the second largest oilfield in China, a large part of the city's economy revolves around petroleum (https://en.wikipedia.org/wiki/Dongying). In addition, Dongying city contributes large amounts of farmed aquaculture products (Chang \& Chen, 2008), which has become the fastest growing subsector within the agricultural economy in China over the past two decades (Liu, 2008).

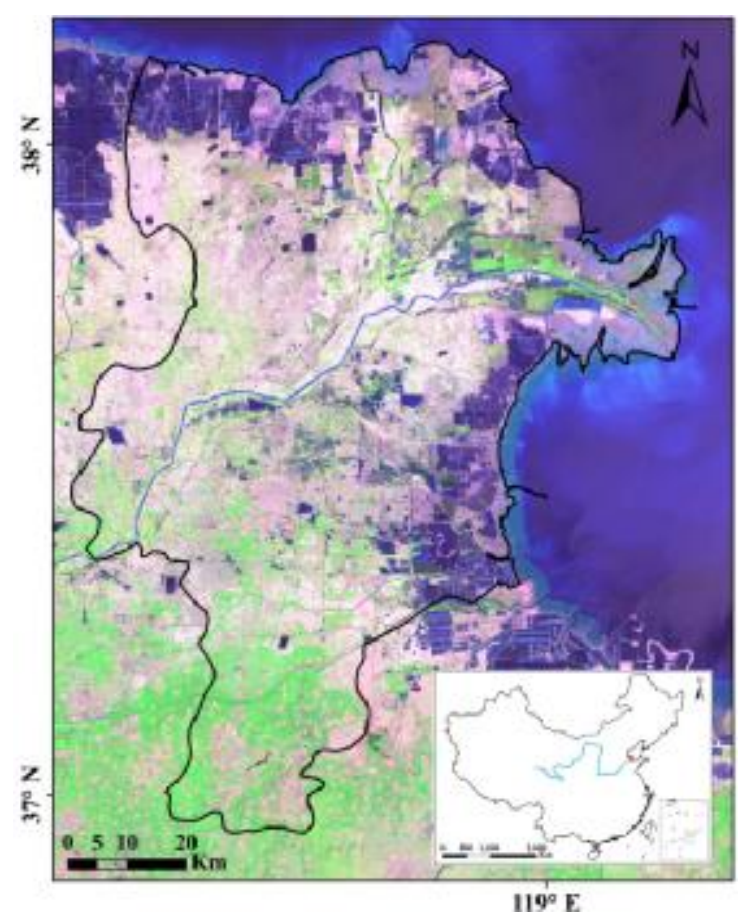

Figure 1 Location of the Study area in 2013.

\section{Data and methods}

Historical information obtained from the library of Institute of Geographic Sciences and Natural Resources Research, Chinese Academy of Sciences, together with statistics data were collected to study the change pattern of mouth channel since 1855. Meanwhile, the YRD outlines along the coastal zone were delineated by visual interpretation of Landsat images obtained on the similar date of 2006, 2009 and 2013 (Table 1). These three images were downloaded from the United States Geological Survey (USGS, http://glovis.usgs.gov). In addition to the main data source, high-resolution image obtained from Google Earth ${ }^{\circledR}$ and statistics information were collected to better detecting the change dynamics of YRD. 
Table 1. Metadata of Landsat images covering the study area

\begin{tabular}{ccc}
\hline Sensor & Date (mm-dd-yyyy) & Resolution $(\mathrm{m})$ \\
\hline Landsat TM 5 & $05 / 20 / 2006$ & 30 \\
Landsat TM 5 & $05 / 30 / 2009$ & 30 \\
Landsat TM 5 & $05 / 30 / 2013$ & 30 \\
\hline
\end{tabular}

Change detection analysis for temporal sequences of images depends on positional accuracy. Hence, before regular processing, all the images were rectified to a UTM projection (Zone 48N, Datum WGS-84) using nearest neighborhood resampling technique, based on 45 evenly distributed ground control points. After rectification, all the images had a registration error of less than 0.5 pixels. To reduce atmospheric distortions from scattering and absorption (Song et al., 2001), atmospheric correction was conducted for each Landsat image with the ATCOR 2 software package (Richter, 2011). The ATCOR model calculates sensor-specific atmospheric look-up tables based on MODTRAN 5 codes (Berk et al., 2008). After preprocessing procedure, the YRD outlines were extracted by visual interpretation of Landsat images three times to minimize the uncertainty of glacier area estimating, and they were further processed using spatial analysis tools of ArcGIS 10.1 to detect the area change during 2006-2013. In those cases that the boundary of YRD was difficult to confirm, the modified soil adjusted vegetation index (MSAVI) was selected as auxiliary means to more accurately extracting the results. The equation of MSAVI is shown as follows:

$M S A V I=(2 N I R+1-\sqrt{(2 N I R+1)-8(N I R-R)}) / 2$

Where NIR is the infrared band of Landsat image, and $R$ represents the red band. The calculation of MASVI can be operated using band math function in ENVI 5.1 software.

\section{Mouth channel migration since 1855}

Since the Yellow River changed trajectory of its lower reaches into Bohai Sea in 1855, its mouth channel has had migrated ten times (Figure 2). During 1855-1889, the mouth channel of Yellow River was located in the up-middle part of YRD (Poinsettia red lines). After that, the mouth channel moved southwards during 1889-1897 (Seville orange lines) and 1897-1904 (Citroen Yellow lines). However, in the period of 1904-1926 (Macaw green lines) and 1926-1929 (Chrysophase lines), it moved to the northwest part of YRD, emptying into the Bohai Sea via Tuhai River. After a period of southward-northwestward migration, the Yellow river began a new course of change trend from south to north during 1929-1976: In the period of 1929-1934 (Moorea blue lines), the mouth channel of the Yellow River migrated to the south edge of YRD, and the Zhimaigou River became its new mouth channel. In the period of 1934-1953 (Anemone violet lines), the Tianshuigou mouth is the new channel into Bohai Sea. Since 1953, the Yellow River moved northward, seizing Shenxiangou as the channel connecting the sea until 1964 (Peony pink lines). From 1964-1976, it migrated further to the north part of YRD (Dark umber lines), connecting the Bohai Sea via the Diaokouhe River. Since 1976 (Lepidolite lilac lines), the mouth channel of the Yellow River remains in relative stabilization state; in 2005, it was forced to change its estuary from southeast to northeast. Compared to the coastal line in 1855 (grey line in Figure 2), the YRD extended significantly during a 158year period. According to the calculation results of ArcGIS Spatial Analysis tools, from 1855 to 2013, the Yellow River delta has already extended for an area of $3197.29 \mathrm{~km}^{2}$, accounting to $40.35 \%$ area of the YRD in 2013.

\section{Area change of the Yellow River Delta during 2006-2013}

As shown in Section 4, due to the south-north migration courses, the profile of YRD remained a fanshaped area during 1855-1979. After 1979, due to various causes, e.g. the construction of reservoirs and conservation policies implement, the volume of sediment discharge sharped down significantly, 
the mouth channel remains relatively stable, and area of the Yellow River built began to extend eastward into the sea, forming a coracoid-shaped alluvial area.

Comparison of the three Landsat image found that the coastal line change was mainly concentrated on the east part of the coastal zone. According to the auxiliary data, due to the constructions of dykes to protect (I) Dongying Harbor facility region, (II) marine aquaculture zones, and (III) Shengli oil field, area of these coastal regions remains almost unchanged; the only region for the Yellow River to rebuild is the estuary region, which is labeled Region IV in Figure 3. Hence, the estuary regions were identified from 2006, 2009 and 2013 images and outlines of this region were depicted and shown in Figure 4. Due to the estuary migrating northeastward, the sediment discharge showed an evident negative mass balance, the area of this part reduced significantly. In contrast, the north part of estuary region displayed significant sediment accumulation as the mouth of Yellow River migrating westwards during 2006-2009 and 2009-2013 periods. Overall, the area of estuary region in 2006 was $465.10 \mathrm{~km}^{2}$ (Poinsettia red polygon in Figure 4), $395.92 \mathrm{~km}^{2}$ in 2009 (Quetzel green polygon), reduced $69.18 \mathrm{~km}^{2}(-14.87 \%$ than that of 2006); during 2009-2013, it decreased with a rate of $6.58 \%\left(26.07 \mathrm{~km}^{2}\right)$ to $369.85 \mathrm{~km}^{2}$ in 2013 (Dark Amethyst polygon), displaying a decelerating recession trend. Overall, the area of YRD in 2013 is receded $86.25 \mathrm{~km}^{2}$ since 2006 (18.54\%).

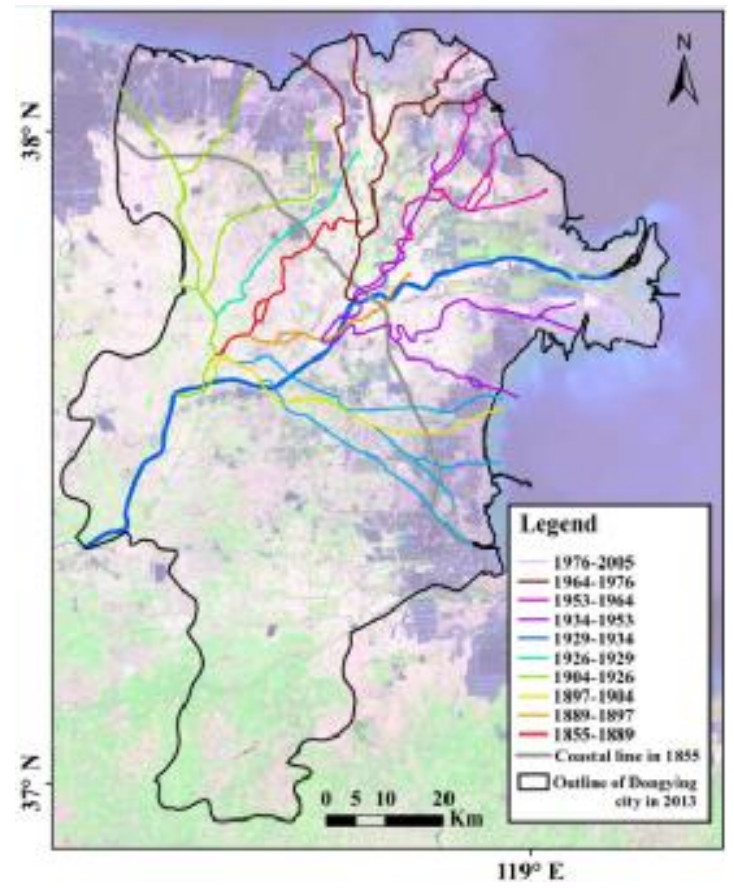

Figure 2. Mouth channel change of the Yellow River since 1855.

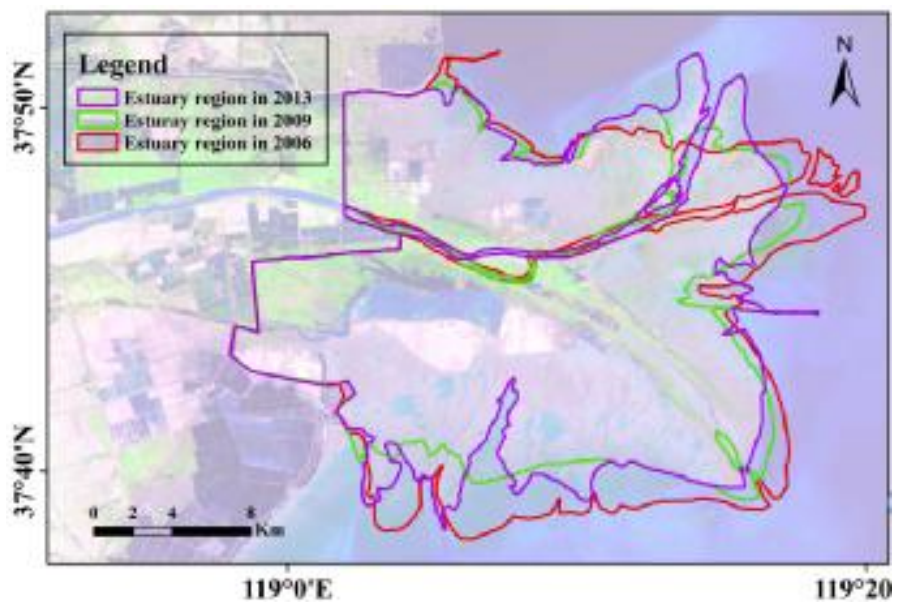

Figure 3. Dynamic change of the estuary region during 2006-2013. 


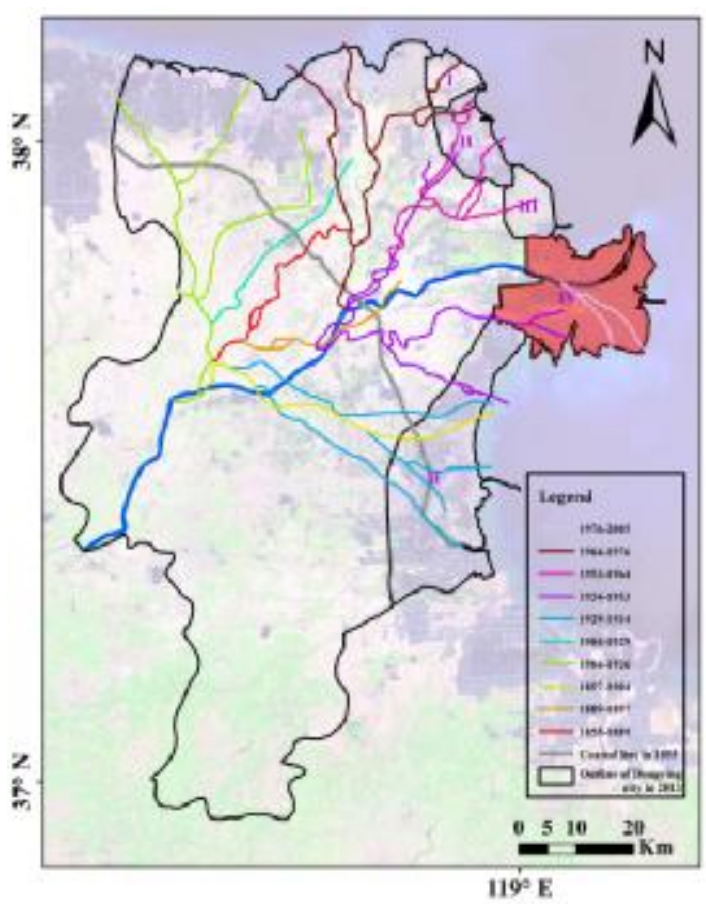

Figure 4. Change region of the YRD coastal zone.

\section{Conclusion and discussion}

With the aid of remote sensing imagery and RS/GIS analysis methods, land cover change can be identified and monitored more easily and efficiently. During the investigated period during 18552013 and 2006-2013, the Yellow River Delta experienced immense changes. The results of the statistics data and spatial analysis on Landsat TM data demonstrated two obvious characteristics:

- Since the Yellow River changed trajectory into Bohai Sea in 1855, its mouth channel has had migrated ten times: Before 1976, the Yellow River experienced a course of migrating from north to south and back to north part of YRD; after 1976, the mouth channel remained in relative steady state.

- Results from RS images and spatial analysis found that the area of YRD decreased $86.25 \mathrm{~km}^{2}$ (18.54\%) compared to that in 2006, the area of YRD is turning to recession.

Furthermore, since this study presented a view converse to the conventional notion that "the YRD is still growing", more data and images were recommended for more detailed investigation. However, considering land erosion will bring about various ramifications such as sea water intrusion and soil salinization (Renaud \& Kuenzer, 2012), which may in turn affect the natural resources and local population will have to adapt to the new circumstances (Kuenzer et al., 2012), decision makers shall implement efficient and effective measures to combat land decreasing.

\section{References}

[1] Berk, A., et al. 2008. MODTRAN5.2.0.0 user's manual. Hanscom, MA and Burlington, MA: Spectral Sciences Inc., Air Force Research Laboratory.

[2] Chang, Y., \& Chen, J. 2008. The status of mariculture in northern China. In FAO/NACA regional workshop on the future of mariculture: A regional approach for responsible development in the Asia-Pacific region, 7-11 March 2006, Guangzhou, China (pp. 271-284).

[3] Kuenzer, C., Ottinger, M., \& Dech, S. 2012. Coastal zone dynamics of the Yellow River Delta e earth observation based diagnosis. In Proceedings of the $32^{\text {nd }}$ EARSeL symposium and 36th general assembly 2012-05-21 until 2012-05-24, Mykonos, Greece. 
[4] Liu, Y. 2008. In FAO/NACA regional workshop on the future of mariculture: A regional approach for responsible development in the Asia-Pacific region, 7-11 March 2006, Guangzhou, China.

[5] Milliman, J.D., \& Meade, R.H. 1983. World-wide delivery of river sediment to the oceans. The Journal of Geology 1-21.

[6] Ottinger M., et al. 2013. Monitoring land cover dynamics in the Yellow River Delta from 1995 to 2010 based on Landsat 5 TM. Applied Geography 44: 53-68.

[7] Peng, J., Chen, S., \& Dong, P. 2010. Temporal variation of sediment load in the Yellow River basin, China, and its impacts on the lower reaches and the river delta. Catena 83(2): 135-147.

[8] Renaud, F., \& Kuenzer, C. 2012. Introduction. In F. Renaud, \& C. Kuenzer (Eds.), The Mekong delta system e Interdisciplinary analyses of a river delta (pp. 3-6). Springer.

[9] Richter, R. 2011. Atmospheric/topographic correction for satellite imagery ATCOR-2/3 user guide. DLR IB 565-01/11. Wessling, Germany.

[10]Song, C., et al. 2001. Classification and change detection using Landsat TM data: when and how to correct atmospheric effects? Remote Sensing of Environment 75: 230-244.

[11]Wang, X., Ren, Z., \& Tan, K. 2007. Eco-environmental evaluation with remote sensing in the middle and upper areas of the Yellow River drainage basin. International Journal of Remote Sensing 28(17): 3937-3951.

[12]Wang, W., et al. 2012. Predicating energy demand and carbon emissions of the Yellow River Delta high-efficiency eco-economic zone. Energy Procedia 14: 229-234.

[13] Wonsuck K. 2012. Flood-built land. Nature Geoscience 8: 521-522.

[14]Ye, Q., et al. 2004. Geospatial-temporal analysis of land-use changes in the Yellow River Delta during the last 40 years. Earth Sciences 47(11): 1008-1024. 